\title{
Correction to: Hellish Evil, Heavenly Love: A Long-Term History of Same-Sex Sexuality and Religion in the Netherlands
}

\author{
David J. Bos
}

\section{Correction to:}

Chapter 2 in: M. Derks and M. van den Berg (eds.), Public Discourses About Homosexuality and Religion in Europe and Beyond, https://doi.org/10.1007/978-3-030-56326-4_2

The original version of this chapter was inadvertently published with references that appeared in the eBook version without cross-links to the online databases. The references Ayoub 2016; Bego 2015; Derks 2019; Dudink 2011; Köttig, Bitzan, and Petö 2017; Rohde 2005; Slootmaeckers, Touquet, and Vermeersch 2016; Sremac and Ganzevoort 2015a; and Sremac and Ganzevoort 2015b have now been correctly updated. The corrections to the book have been updated with the changes.

The updated version of this chapter can be found at https://doi.org/10.1007/978-3-030-56326-4_2 